\title{
NOTE
}

\section{New 'biodiversity' measures reveal a decrease in taxonomic distinctness with increasing stress}

\author{
R. M. Warwick*, K. R. Clarke \\ Plymouth Marine Laboratory, Prospect Place, West Hoe, Plymouth PL1 3DH, United Kingdom
}

\begin{abstract}
We demonstrate a continuous decrease in the taxonomic distinctness of a marine assemblage along a gradient of increasing environmental contamination, in a situation where species diversity remains constant. Two indices have been employed, $\Delta$ and $\Delta^{*}$, the furst being a taxonomic diversity index empirically related to Shannon species diversity $\left(H^{\prime}\right)$ but with an added component of taxonomic separation, and the second a measure purely of taxonomic distinctness. The values of both indices appear to be rather less influenced by sample size than does $H$, and markedly less sample-size dependent than other common diversity measures such as species richness and evenness. It is concluded that taxonomic distinctness may be a more sensitive univarlate undex of community perturbation than species diversity. We also argue that $\Delta$ comes closer to a 'biodiversity' index than $H$, and suggest the possibility that the total genetic complement in any biome may, within limits, remain more or less constant but be partitioned differently among the hierarchy of taxonomic units, according to the age or successional stage of the assemblage.
\end{abstract}

KEY WORDS: Taxonomic distinctness - Hierarchical classification - Biodiversity Environmental perturbation - Macrobenthos

In grossly perturbed situations, communities are kept in an early successional stage with a low species diversity, and often comprise guilds of closely related species or single species with a high genetic diversity. For example, there is a remarkable concordance between the soft-bottom macrobenthic taxa listed by Pearson \& Rosenberg (1978) as characterising organically polluted habitats (their Table 1 b) and those macrobenthic genera listed by Knowlton (1993) as having sympatric sibling species (her Table 1), which clearly links these phenomena either directly or indirectly. Meiobenthic examples include the copepod genus

•E-mail: r.warwick@pml.ac.uk
Tisbe (Bergmans 1979), the polychaete genus Ophryotrocha ( $\AA$ kesson 1994) and the nematode family Oncholaimidae (Bett \& Moore 1988), all of which characterise organically polluted habitats and have sympatric sibling species. Unperturbed benthic communities in a late successional stage tend to comprise a range of more distinct species belonging to many phyla. In less severely perturbed situations, changes in community composition in response to anthropogenic disturbances of various kinds, which are unaccompanied by changes in species diversity, have repeatedly been revealed by multivariate analysis of species abundance data (e.g. Gray et al. 1990, Warwick \& Clarke 1991, Dawson Shepherd et al. 1992). Species diversity seems in some way to be homeostatic, at least to relatively low levels of disturbance. However, assemblages with the same species diversity may comprise species which are all closely related to each other taxonomically (belonging to the same genus or family) or be taxonomically more distinct (belonging to different phyla), i.e, the hierarchical level of diversity may shift even though species diversity is maintained. Clearly, the concept of a lowering of the hierarchical level of taxonomic diversity with increasing level of perturbation could be extended below the species level by genetic analysis, but determination of genetic diversity of all species is impracticable in species-rich communities. We therefore confine ourselves here to the taxonomic structure above the species level.

Methods and results. Previous measures of taxonomic relatedness or distinctness developed for conservation purposes have been based purely on the topology of cladistic classifications (May 1990, VaneWright et al. 1991). Detailed, fully resolved cladograms are not available for most groups of organisms, and a more pragmatic approach is to use currently accepted hierarchical Linnean classifications. However, a topo- 
logical approach takes no account of the relative abundances of species or the actual taxonomic level at which 2 species are related. For example, a sample consisting of 5 species, all from different phyla, has the same topological structure as one in which the 5 species are all from the same genus. For an ecologically meaningful measure of the taxonomic distinctness in a natural assemblage of organisms, or in a sample of that assemblage, information on numbers of individuals and absolute taxonomic level should clearly be utilised. We have employed 2 indices, $\Delta$ and $\Delta^{\bullet}:$ the first can be described as a taxomomic diversity index, since it is empirically related to Shannon species diversity $H^{\prime}$ (Pielou 1975) but has an added component of taxonomic separation; the second can be thought of as a measure purely of taxonomic distinctness, without the contribution from species diversity.

Letting $x_{i}$ denote the abundance of the $i$ th species $(i=1, \ldots, S)$ and $w_{1}$ the 'distinctness weight' given to the path length linking species $i$ and $j$ in the hierarchical classification, then taxonomic diversity $\Delta$ is defined simply as the average (weighted) path length between every pair of individuals:

$$
\Delta=\frac{\sum \sum_{i<j} w_{i j} x_{i} x_{j}+\sum_{i} 0 \cdot x_{i}\left(x_{i}-1\right) / 2}{\sum \sum_{i<j} x_{i} x_{j}+\sum_{i} x_{i}\left(x_{i}-1\right) / 2}
$$

where the null second term in the numerator has been included to emphasise that the weight for the path linking individuals of the same species is taken to be zero. The taxonomic distinctness $\Delta^{*}$ is then defined as $\Delta$ divided by the value it takes when the hierarchical tree has the simplest possible structure, that of all species belonging to the same genus. It is readily seen that an equivalent definition of $\Delta^{*}$ is as the average (weighted) path length, ignoring paths between individuals of the same species (in denominator as well as numerator), so that

$$
\Delta^{*}=\frac{\sum \sum_{1<j} w_{i j} x_{1} x_{j}}{\sum \sum_{i<j} x_{1} x_{j}} \equiv \frac{\sum w_{k} f_{k}}{\sum f_{k}}
$$

In the latter form, the sums are over $k=1, \ldots, K$, where $K$ is the number of hierarchical taxonomic levels, $\left\{f_{k}\right\}$ are the sums of cross-products of counts from all pairs of species connected at the same hierarchical level, and $\left\{w_{k}\right\}$ the corresponding path weights (Fig 1). For the sake of definiteness, $w$, (species within the same genus) is always set to unity and the examples below then use a simple linear scale: $w_{2}=2$ (species within the same family but different genera), $w_{3}=3$ (species within the same order but different family), ... to $w_{6}=6$ (species in different phyla). It is clear from this simple definition that 2 samples with the same species abundance distribution, and thus an identical suite of standard diversity indices (Pielou 1975), can take values of $\Delta^{*}$ across the full range $1 \leq \Delta^{*} \leq 6$. As noted above, the extremes, of all species in the same genus $\left(\Delta^{*}=1\right)$ and all species in different phyla $\left(\Delta^{*}=6\right)$, are topologically identical, so that an index based purely on the topology would be unhelpful in this context. It is apparent from Eq. (2) that $\Delta^{*}$, unlike $\Delta$, is scale-independent and so generalises straightforwardly to data matrices which are not of species counts but biomass or \% substratum cover, and also encompasses downweighting of counts by transformation (including reduction to presence/absence, when an analysis based purely on the taxonomic hierarchy will result).

As a simple example of the computation in Eqs. (1) \& (2), assume that the data pictured in Fig. 1 comprises a complete sample, i.e. with abundances of $x_{1}=5, x_{2}=3$, $x_{3}=3, x_{4}=1, x_{5}=3$ for the $S=5$ species observed. Then, using weights $w_{0}=0, w_{1}=1, w_{2}=2$, the total path length between all pairs of individuals is:

$$
\begin{aligned}
1 .\left(x_{1} x_{2}\right. & \left.+x_{4} x_{5}\right)+2 \cdot\left(x_{1} x_{3}+x_{1} x_{4}+x_{1} x_{5}+x_{2} x_{3}+\ldots+x_{3} x_{5}\right) \\
& =13.5
\end{aligned}
$$

The total number of paths connecting all pairs of individuals of different species is:

$$
x_{1} x_{2}+x_{1} x_{3}+x_{1} x_{4}+x_{1} x_{5}+x_{2} x_{3}+\ldots+x_{4} x_{5}=74
$$

and of all pairs of individuals within the same species is:

$$
x_{1}\left(x_{1}-1\right) / 2+x_{2}\left(x_{2}-1\right) / 2+\ldots+x_{5}\left(x_{5}-1\right) / 2=17
$$

The taxonomic diversity is then defined as the average path length: $\Delta=135 /(74+17)=1.48$, and the taxonomic distinctness $\Delta^{*}$ as the average path length, 



Species diversity $\left(H^{\prime}\right)$

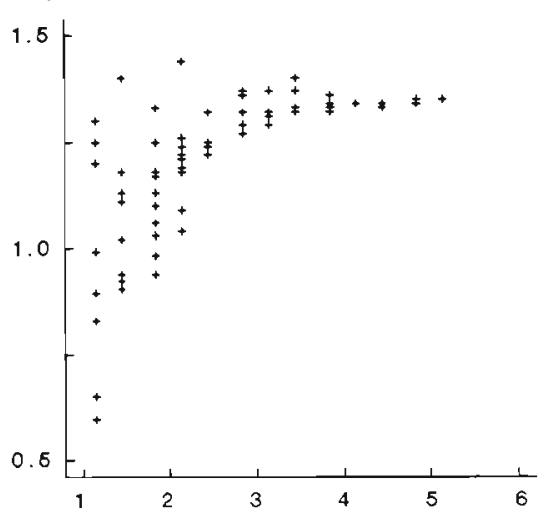

Species richness (D)

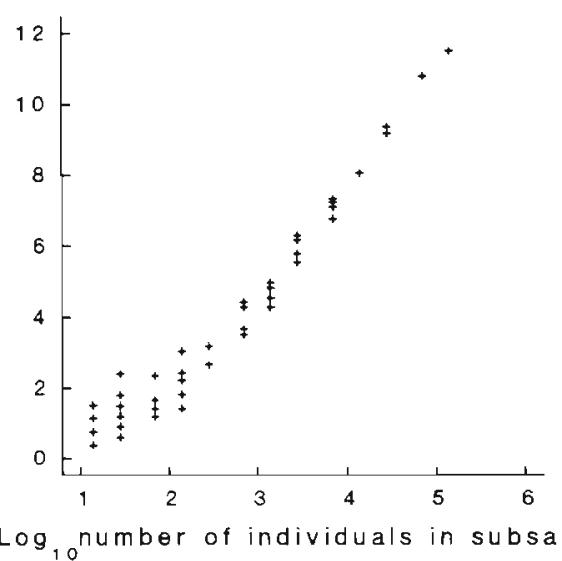

Evenness (J)

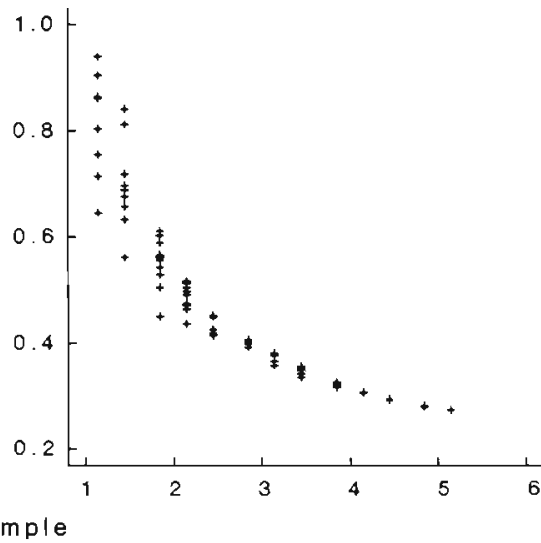

Fig. 2. Univariate indices of community structure based on computer-simulated subsamples of different numbers of individuals from a large sample of macrobenthos taken in the Bay of Morlaix, France

ignoring the within-species paths of Eq. (5), namely $\Delta^{*}$ $=135 / 74=1.82$.

In a variety of small-scale special cases, $\Delta$ and $\Delta^{*}$ give values that appear to agree well with intuitive assessments of taxonomically based diversity and pure taxonomic distinctness, respectively. It is also of importance to examine the extent to which the mean values of both indices are dependent on sample size. In Fig. 2, the univariate indices of community structure are based on computer-simulated subsamples of different numbers of individuals, without replacement, from a large sample comprising the summation of 5 sets of 10 grab samples of macrobenthos taken in the Bay of Morlaix, France, between May 1977 and February 1978, a period of minimal community change (Dauvin 1984). The total number of species recorded was 257. Note that the mean values of $\Delta$ and $\Delta^{*}$ are virtually independent of the number of individuals, whereas species richness (Margalef's D) and evenness (Pielou's $J$ ) are strongly sample size-dependent, with $H^{\prime}$ less so. In a number of other examples we have examined, $\Delta$ has been broadly shown to track changes in $H^{\prime}$ but, as expected from its construction, $\Delta^{*}$ bears no particular relation to species diversity.

We have applied these indices to data from a grabsampling survey of the macrobenthos in the vicinity of the Ekofisk oil field in the North Sea (Gray et al. 1990 , Warwick \& Clarke 1991), an area where natural environmental conditions and community composition are very uniform and provide low background noise against which anthropogenic perturbations to community structure can be assessed. Grab samples were taken from the sea bed in a star-shaped pattern of 39 stations radiating from the active centre of drilling (Fig. 3, top left). A non-metric multidimensional scaling ordination (MDS) of abundances of the 209 species (Fig. 3, top right) shows a clear gradation of community change from stations $<250 \mathrm{~m}$ from the centre (designated 1), through stations $250 \mathrm{~m}$ to $1 \mathrm{~km}$ away (2), 1 to $3.5 \mathrm{~km}$ away (3), to the most distant stations $>3.5 \mathrm{~km}$ away (4). Distance from the drilling centre correlates closely with levels of contaminants derived from drilling muds (e.g. barium and petroleum hydrocarbons) in the bottom sediments. Taxonomic diversity and 



Fig. 3. Analyses of data on the macrobenthos of the Ekofisk oil field in the North Sea. Top left: map of sampling stations. Top right: non-metric multidimensional scaling ordination (MDS) of species abundances with stations (1) $<250 \mathrm{~m}$ from the centre, (2) $250 \mathrm{~m}$ to $1 \mathrm{~km}$ away, (3) $1 \mathrm{~km}$ to $3.5 \mathrm{~km},(4)>3.5 \mathrm{~km}$ away. Middle row: taxonomic diversity $(\Delta)$ and taxonomic distinctness ( $\Delta$ ") plotted against distance $(\log s c a l e)$ from the centre of oil-drilling activity. Bottom row: similar plots for the Shannon species diversity index $\left(H^{\prime}\right)$, species richness (Margalef's $D$ ) and evenness (Pielou's $J$ )

taxonomic distinctness plotted against distance (log scale) from the centre of oil-drilling activity (Fig. 3, middle row) show a continuous increase, the slope for $\Delta$. being steeper than that for $\Delta$. Values for the 4 stations less than $150 \mathrm{~m}$ from the centre are not included in the calculation of the regression lines: for $\Delta, F=29,2, p=$ 0.00001 ; for $\Delta^{\bullet}, F=37.0, p<0.00001$. The indices are based on a standard classification (Howson 1987) and use the taxonomic levels of species, genus, family, order, class and phylum, as described above. Similar plots for $H^{\prime}, D$ and $J$ are completely flat, for samples further than $150 \mathrm{~m}$ from the centre (Fig. 3, bottom row): for $H^{\prime}$, $F=0.65, p=0.43$ (ns); for $D, F=0.83, p=0.37$ (ns); for $J$, $F=1.4, \mathrm{p}=0.25(\mathrm{~ns})$.
Discussion. Multivariate analyses show that in the Ekofisk example there was a clear change in community composition occurring as far as $3 \mathrm{~km}$ away from the centre of drilling activity, but species diversity, richness and evenness were only affected very close to the centre $(<150 \mathrm{~m}$ ). Taxonomic distinctness, however, continued to rise linearly with increasing (log) distance from the centre, out to several kilometres. Taxonomic diversity, comprising components of both species diversity and taxonomic distinctmess, also continued to rise, but less steeply. The taxonomic hierarchy comprising species, genus, family, order, etc. is somewhat arbitrary, of course, as is the allocation of the linear scale of weightings 1 to 6 to these designations. It is 
therefore important to realise that, as with most (if not all) diversity indices, $\Delta$ and $\Delta^{*}$ are relative measures, for use in comparisons within a study rather than having some absolute global validity. In this role, $\Delta^{*}$ is by far the most sensitive univariate measure of community structure that we have examined for these data.

'Biodiversity' cannot be equated with species diversity, but can be considered as the sum of the taxonomic or numerical diversity, and the ecological, genetical, historical and phylogenetic diversity' (Van der Spoel 1994). Clearly, all these different elements are impossible to encapsulate objectively in the same units to provide a single 'biodiversity' index, but we believe that $\Delta$ comes closer than $H^{\prime}$, in that more of these elements are included

Evidence is now accumulating that genetic diversity is higher in species which characterise unstable stressed environments, as opposed to their counterparts from more stable conditions (Nevo et al. 1984). This, together with the evidence provided here, begins to suggest the intriguing possibility that the total genetic complement in any biome may, within limits, remain more or less constant but be partitioned differently among the hierarchy of taxonomic units, according to the age or successional stage of the assemblage. Still more speculatively, the phenomenon of increased taxonomic distinctness with increasing environmental stability may also be evident over an evolutionary, as well as an ecological, time scale. In the marine realm there are 34 phyla; although these vary in their total numbers of species, none of them is overwhelmingly predominant. On the other hand, the terrestrial biota, which has been subjected over the last 450 million years to a much higher degree of environmental variability than that present in the sea, comprises only 15 phyla, with more than $90 \%$ of the species belonging to the phylum Arthropoda (Briggs 1994)

Acknowledgements. This work results from the Marine Biodiversity project of the Plymouth Marine Laboratory, Natural Environment Research Council, UK, and constitutes an initial stage in a study on development and measurement of biodiversity indices for the marine environment, part-funded by

This note was submitted to the editor the UK Ministry of Agriculture, Fisheries and Food (project no. AE07 13).

\section{LITERATURE CITED}

Akesson B (1984) Speciation in the genus Ophryotrocha (Polychaeta, Dorvilleidae). Fortschr Zool 29:299-316

Bergmans M (1979) Taxonomic notes on specles of Tisbe (Copepoda: Harpactıcoida) from a Belgian sluce dock Zool Scr 8:211-220

Bett BJ, Moore CG (1988) The taxonomy and biology of a new species of Pontonema (Nematoda, Oncholaimidae) dominant in organically polluted sublittoral sediments around Scotland, with a review of the genus. J nat Hist 22 : $1363-1377$

Briggs JC (1994) Species diversity: land and sea compared. Syst Biol 43:130-135

Dauvin JC (1984) Dynamique d'écosystemes macrobenthiques des fondes sédimentaires de la Baie de Morlaix et leur perturbation par les hydrocarbures de l'Amoco Cadiz. Univ Pierre et Marie Curie, Paris

Dawson Shepherd AR, Warwick RM, Clarke KR, Brown BE (1992) An analysis of fish community responses to coral mining in the Maldives. Environ Biol Fish 33:367-380

Gray JS, Clarke KR, Warwick RM, Hobbs C (1990) Detection of initial effects of pollution on marine benthos: an example from the Ekofisk and Eldfisk oilfields, North Sea. Mar Ecol Prog Ser 66:285-299

Howson CM (ed) (1987) Species directory to British marine fauna and flora. Marine Conservation Society, Ross-on-Wye

Knowlton N (1993) Sibling species in the sea. A Rev Ecol Syst $24: 189-216$

May RM (1990) Taxonomy as destiny. Nature 347:129-130

Nevo E, Beiles A, Ben-Shlomo R (1984) The evolutionary significance of genetic diversity: ecological, demographic and life history correlates. In: Mani GS (ed) Evolutionary dynamics of genetic diversity. Lecture notes in biomathematics 53. Springer-Verlag, Berlin, p 13-213

Pearson $T H$, Rosenberg $R$ (1978) Macrobenthic succession in relation to organic enrichment and pollution of the marine environment. Oceanogr mar Biol A. Rev 16 $229-311$

Pielou EC (1975) Ecological diversity. Wiley, New York

Van der Spoel S (1994) A biosystematic basis for pelagic biodiversity. Bijdr Dierk 64:3-31

Vane-Wright RI, Humphries CJ, Williams PH (1991) What to protect? Systematics and the agony of choice. Biol Conserv 55:235-254

Warwick RM, Clarke KR (1991) A comparison of some methods for analysing changes in benthic community structure J mar biol Ass UK 71:225-244

Manuscript first recelved: April 28, 1995

Revised version accepted: June 26, 1995 